\title{
Cohesive Properties of Modal Adverbs
}

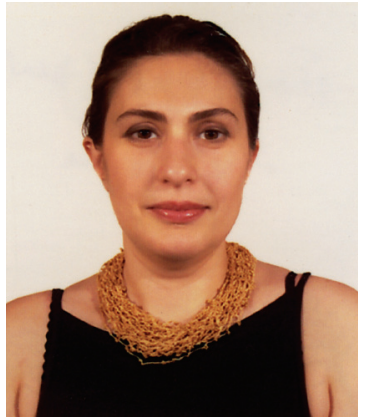

Naira Martirossyan

Cohesion is an essential property of a text, which helps distinguish text from non-text. Cohesion is more than a mere sum of its constituent parts. Interpreting the concept of cohesion V.Bogdanov makes the following comparison: it is like a million of crystal particles which if taken in isolation can be easily blown off, whereas viewed as a whole unified piece it may undergo only slight vibration (Bogdanov 1977). How is linguistic cohesion achieved? M. Halliday and R. Hasan regard the concept of cohesion as a semantic unit, referring it to relations of meaning that exist within the text and that define it as text. Like other semantic relations, cohesion is expressed through the stratal organization of language, grammar and vocabulary in particular. Therefore these authors speak of grammatical cohesion and lexical cohesion (Halliday and Hasan 1976).

The many researches related to the study of modal adverbs are done on the sentence level, the text level being in the shade. I. Galperin focuses his attention on the study of text modality claiming that modality is the essence of communication process which can be expressed by elements of different language levels: grammar, lexis, stylistics, etc. (Galperin 1981:30).

The purpose of the present paper is to view modal adverbs as text-creating elements. Modal adverbs constitute a lexical-grammatical means of expressing the category of modality in English. Linguists usually acknowledge two types of modality: subjective (modality de dicto) and objective (modality de re). The first type implies the attitude of the speaker to the content of the utterance, while the second type presupposes the attitude of the speaker to reality. Modal adverbs are used to express subjective or epistemic modality. In this function modal adverbs may refer not only to the whole utterance, but also to its constituent parts. Below are examples to illustrate this:

a) Perhaps being Jewish is not something you can remove like a change of clothing.

(Segal)

b) I might also become something else, instead of an actor-singer, perhaps a lawyer, like my brother.

(Baldwin)

As is seen from the examples, the first 'perhaps' refers to the whole sentence, whereas the second 'perhaps' is related to the predicative (sentence b).

Though the sentence and the text refer to different lingual units, the modality of the latter is composed of the modal semantics of the sentences making up the text. This, 
however, does not mean that text modality is the mechanical sum of modalities of individual sentences (Bubnova 1984 :35). Text modality and sentence modality have their specific features and this requires a detailed study. Let's consider the following example:

Fortunately, there is a diversity of major industries in California, including defense, aerospace, agriculture, tourism and entertainment (1). The number of new jobs has been pretty well among them (2). Because of our large population, we developed a huge labor market which attracts investors in the high technology, electronics and computer industries (3). We work hard at making conditions for them so that they prefer to operate in California rather than in any other area (4).

$$
\text { (“Aim”, No. 10) }
$$

If we view the modal adverb 'fortunately' on the sentence level, we will imagine that the speaker is satisfied only with the fact that there are various industries in California (sentence 1). In fact, he is content with the idea that this fact leads to creating new jobs (sentence 2), since it becomes possible to enlarge the labor market, which can attract investors in the high technology and other industries (sentence3). And finally (which is more important), they will work hard so that the investors choose to work in California instead of another place (sentence 4). So the last circumstance may be considered their ultimate purpose, the fortunate output of their efforts, which makes the use of the adverb 'fortunately' in this context quite plausible. All the sentences making up this fragment of the text are linked together through their modal-semantic relations, thus creating a whole unity. As G.Kolshanski puts it, we observe the so- called 'chaining of sentences' (Kolshanski 1978:30).

We propose to term this fragment of the text in which the modal adverb attracts the preceding and succeeding sentences a Modal-Evaluative Complex (MEC for short). By its form and structure a MEC can be viewed as a supraphrasal unity and like it, it usually includes more than one sentence.

In this paper we will examine the use of modal adverbs on the MEC level.

The modal adverbs linking the components of a MEC express various semantic relations, anaphora and cataphora included. As is known, anaphora implies retrospective connection, while cataphora indicates prospective connection. Below are examples illustrating these two types of connection.

Anaphora: $\quad$ This was a foul little place (1).

Unfortunately, she was really hungry, having had a very small lunch (2).

(Priestley)

As we see from the example, the modal adverb 'unfortunately' used in he first sentence is not associated with the fact that the woman was hungry (1). Rather, the unfortunate circumstance was caused by the fact that the woman had to eat in that disgustful eating-place (sentence 2). 
Cataphora: $\quad$ Fortunately, the mad musketeer had gone to sleep (1). And a weary Danny Rossi followed thereafter unnoticed (2).

(Segal)

In this example we see that the fortunate situation was created for Danny (sentence 2) thanks to the fact that the musketeer had gone to sleep (sentence 1).

Let's consider another example taken from "Death of a Hero" by R. Aldington.

The English poets and foreign painters were his only real friends. They were his interpreters of the mystery, the defenders of the inner vitality, which he was fighting unconsciously to save. Naturally, the School was against him.

(Aldington)

Taken out of context, the last sentence does not explain why it was natural for the School to behave so. To understand it, the reader has to go back to the previous sentences. But even so, it will not give the complete reason for the negative attitude of the school teachers towards George. It is a larger context that helps the reader fully understand how the matters stand. And here we come across the following lines: "He (George) got a very bad report that term. For which he was duly lectured and reprimanded". Or prior: "He was supposed (according to the school teachers' report) to be dull-minded as well as obstinate and unmanly..." Or: The head master said: "You take little or no interest in the school life and your games record is abominable... Your form master reports that you have a thousand lines of impositions yet to work off." Considering this character sketch given to George by his teachers, we can easily understand why the author uses the modal adverb 'naturally' in the cited example.

Of special interest is the following example taken from "Mrs. Dalloway" by V. Woolf:

Clarissa once, going on top of an omnibus with him somewhere, Clarissa superficially at least, so easily moved, now in despair, now in the best of spirits, all aquiver in those days and such good company, spotting queer little scenes, names, people from the top of a bus, for they used to explore London and being back bags of treasures from the Caledonian market - Clarissa had a theory in those days - they had heaps of theories, always theories, as young people have. It was to explain the feeling of dissatisfaction; not knowing people; not being known. For how could they know each other? ... Odd affinities she had with people she had never spoken to, some woman in the street some man behind a counter - even trees, or barns. It ended in a transcendental theory which, with her horror of death, allowed her to believe, or say that she believed (for all her skepticism) that since our apparitions, the part of us which appears, are so momentary compared with the other, the unseen part of us, which spreads wide, the unseen might survive, be recovered somehow attached to this person or that, or even haunting certain places, after death. Perhaps - perhaps.

(“Mrs. Dalloway”, 189-190) 
As is seen from the example, this unusual use of the modal adverb 'perhaps' used at the end of the paragraph and separated from it by parcellation does not refer to the last sentence. It is evident that it belongs to the whole passage (a MEC in our case), which describes the heroine's emotional state: her tension, her feeling of uncertainty about the mode of life she has chosen, her way of evaluating people, the unreliability of human relations, the futility of hopes and dreams. Used twice, the adverb 'perhaps' still more emphasizes this feeling of disappointment and disillusion and mysticism that embrace the heroine throughout the whole novel, making her think that her life was perhaps a failure.

Cohesion on the MEC level may be provided by means of repetition of the same modal adverb.

And now that Mrs. Kennicott's been away, maybe she's got over some of her fool ideas. Maybe she realizes that folks simply laugh at her when she tries to tell us how to ruin things.

$$
\text { (Lewis) }
$$

Cohesion may also be realized through repetition of the same syntactic structure containing a modal adverb, the so-called syntactic parallelism.

Perhaps he was killed by General The' because he knew the Caodaists. Perhaps he was killed by the Hoa-Haos for making passes at the General's concubines. Perhaps he was just killed by someone who wanted his money.

(Greene)

In some cases cohesion is provided by the presence of synonymous modal adverbs, showing a slightly different degree of modality as in the following example.

Tubman could not possibly have reached London before Vince and there had been no sign of the D.M. and his wife at breakfast. Probably they were not even going back the same day.

\section{(Mackinlay)}

Modal adverbs may link parts of a MEC, which are characterized by adversative relations. In this case the modal adverb is combined with an adversative conjunction (mainly but), making up double correlative connectives: maybe, perhaps, probably, naturally...+ but.

Here are some examples to illustrate this:

a) "Maybe it makes you smile a little, Father Brown, to find Merton has to live in a fortress like this without even a tree in the garden for anyone to hide behind. But you don't know what sort of proposition we're against in this country."

(Chesterton) 
b) "Perhaps you are right", said the Doctor. "But there shall be music"

$$
\text { (Waugh) }
$$

c) "No doubt the universal secretary knew more about the doctor's name than the doctor did. But even the doctor might have some information about his name."

(Chesterton)

Modal adverbs manifest their text-creating function still more explicitly in dialogues, where they can function as answers to questions in conjunction with 'Yes' and 'No' or without them.

a) -You don't have to account to them for every second of your time, do you?

\section{- Of course not.}

(Waller)

b) "Was Portland referring to a patient when he was making these claims? Steve asked.

"Obviously", Kevin said.

c) - You figure they were Carl's men then?

(F.Cure)

\section{- Evidently.}

\section{(F.Cure)}

In some cases a modal adverb may be used for the purpose of emphasizing the idea expressed in the MEC.

Let's consider the following example:

I don't think I'll be the same after yesterday. The newspapers are calling what happened a 'Greek tragedy'; but to me it's an American tragedy. In fact, it's something I feel so closely that I would call it a death in the family.

(Segal)

Here we observe a stylistic device, the so-called gradation, which indicates a gradual strengthening, spotlighting the message expressed in the text: a Greek tragedy < an American tragedy $<$ in fact + a death in the family.

It is natural that in some cases this expressive use of a modal adverb may entail certain semantic changes in its meaning. This is clearly seen in the following examples. 
a) And though I had bought them out of comparison, after living with them I began to like them.

Indeed, I found a strange beauty in them.

(Maugham)

b) -They have a democracy here.

-Oh, really? Then how does it happen they can't talk?

(Brand)

'Indeed' in (a) acquires a new shade of meaning-moreover; 'really' in (b) expresses disbelief, incredulity. This is incongruent with the theory of H.Weinrich, who says that word meaning in the text may radically differ from that of isolated sentences and that word semantics must be supplemented by text semantics (Weincich, 1963).

So we can conclude that in addition to all kinds of morphological, syntactic and lexical connectives, modal adverbs can also function as text-creating elements and link sentences on the supraphrasal level both in monologue and in dialogue speech. They can also be used for stylistic purposes to spotlight the message of the passage; in some cases they may undergo certain semantic changes.

\section{References:}

1. Halliday, M.A.K.; Hasan, R. (1976) Cohesion in English. Longman.

2. Weinrich, H. (1963) On the Semantic Structure of Language. Cambridge, Mass.

3. Bogdanov, V.V (1977) Semantico-syntaksicheskaya organizatsiya predlojeniya. Leningrad: Izd.: LSU.

4. Bubobova, M.S. (1984) Nekotoriye spetsificheskiye cherti modalnosti teksta // Sbornik nauchnikh trudov MGPIIYA im. M. Toreza. Moskva. Vip. 231.

5. Galperin, I.R. (1981) Tekst kak obyekt lingvisticheskogo issledovaniya, Moskva: Nauka.

6. Kolshanskiy, G.V. (1978) Tekst kak yedinstvo kommunikatsii // Problemi obshchego i germanskogo yazikoznaniya. Moskva: Nauka.

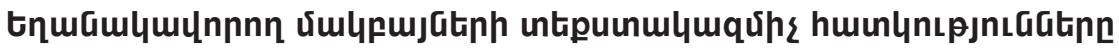

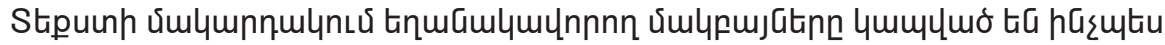

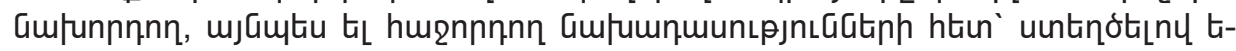

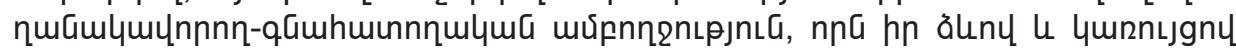

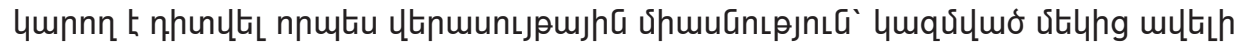

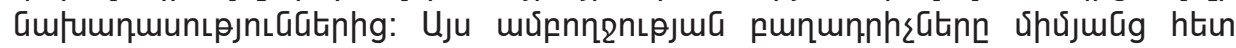

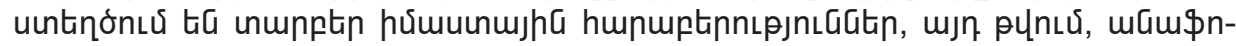

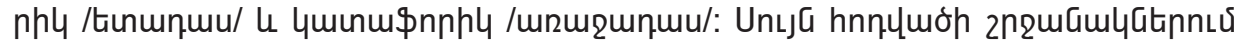

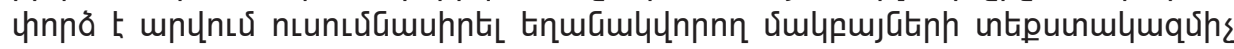

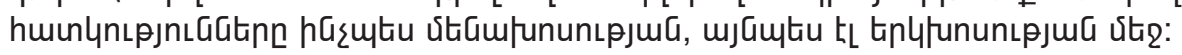

